\title{
The influence of stirring time and frequency of impeller rotation on evaluation of drops dimensions and rheological properties of the multiple emulsion
}

\author{
Marta Major-Godlewska ${ }^{1}$
}

Received: 14 January 2020 / Accepted: 29 March 2020 / Published online: 9 April 2020

(c) The Author(s) 2020

\begin{abstract}
The analysis of drops and rheological measurements of the emulsion produced were presented in the article. The influence of stirring time and rotation frequency on the drops size of the emulsion produced in the propeller of diameter $D=0.1 \mathrm{~m}$ and liquid height $H=0.5 D$ equipped with four standard flat dividers was defined. The Smith turbine stirrer was used to stir the emulsion produced. The drop size was defined for three different propeller rotation frequencies, $500 \mathrm{rpm}, 1000 \mathrm{rpm}$ and $1500 \mathrm{rpm}$. The stirring time, after which the samples were collected, was accordingly $15 \mathrm{~min}$ and $45 \mathrm{~min}$. To produce the emulsion, sunflower oil was used in the oil phase and distilled water in the water phase. There were 6 measurement series all together, and they were presented as the diameter size distribution. The mean arithmetic diameter $d_{\mathrm{a}}$, median $d_{\mathrm{m}}$ and the mean Sauter diameter $d_{32}$ were determined. The rheological measurements of the produced emulsions were presented in graphics as a function $\tau=\mathrm{f}(\gamma)$ and were described as Herschel-Bulkley and Bingham models presented in Table 3 .
\end{abstract}

Keywords Multiple emulsion $\cdot$ Microscopic analysis $\cdot$ Rheological measurements

\section{List of symbols}

$D \quad$ Diameter of the vessel (m)

$d \quad$ Diameter of the drop $(\mu \mathrm{m})$

$d_{\mathrm{a}} \quad$ Arithmetic mean diameter of the drop $(\mu \mathrm{m})$

$d_{\mathrm{m}} \quad$ Median diameter of the drop $(\mu \mathrm{m})$

$d_{32}$ Sauter mean diameter $(\mu \mathrm{m})$

$H \quad$ Liquid height in the vessel (m)

\section{Greek letters}

$\tau \quad$ Shear stress $(\mathrm{Pa})$

$\gamma \quad$ Shear rate $\left(\mathrm{s}^{-1}\right)$

\section{Introduction}

Multiple emulsion is a system of at least two non-stirring with each other liquids, where every another phase is dispersed in the previous phase. Nowadays, when we can observe the increase in food, cosmetics and pharmaceutical

Marta Major-Godlewska

mmajor@zut.edu.pl

1 Faculty of Chemical Technology and Engineering, West Pomeranian University of Technology Szczecin, al. Piastów 42, 71-065 Szczecin, Poland industries, the simplest procedure of emulsion production is very important, the one which may be introduced in these industries. One of the methods of emulsion production is two-step method, during which a singular emulsion in the first step is produced in the apparatus, and then, it is introduced to the continuous phase (the second step). This method was already used in the 1970 s by Matsumoto et al. (1976). Two-step emulsion production method suggested by Matsumoto et al. (1976) was used by Vasiljevic et al. (2006) in his research on characteristics and drug release properties of multiple W/O/W. Two-step multiple emulsion production method, where the first singular emulsion was added to the third continuous phase, was used by Garti (1997), Ursica et al. (2005) and Surh et al. (2007). Research on emulsions produced in two-step method is also conducted by Schuch et al. (2013), Perez-Moral et al. (2014), Bou et al. (2014), Aditya et al. (2015), Sung et al. (2015), Mahammadi et al. (2016), Mehrania et al. (2017), Mutaliyeva et al. (2017) and Yamanaka et al. (2017). Ursica et al. (2005) and Yamanaka et al. (2017) presented the analysis of multiple emulsions drop size produced in two-step method in order to assess the produced emulsions quality and stability. Both Perez-Moral et al. (2014) and Yamanaka et al. (2017) used, among the others, lecithin in the second step of their (W/O/W) emulsion production research. Comparative study of the stability 
of multiple emulsions containing a gelled or aqueous internal phase was presented by Perez-Moral et al. (2014). The research describing the liquid source influence, which was used as a lipid phase of the primary emulsion for riboflavin encapsulation, and physicochemical properties of multiple emulsion were conducted on emulsion produced by Bou et al. (2014) by using the two-step method. In their work, Mahammadi et al. (2016) descried the result of nano-encapsulation of olive leaf extract and its application in soybean oil obtained for emulsions produces in two stages.

The topic of Mehrania et al. (2017) research includes rheological and releasing double nano-emulsion properties containing crocin. Double emulsions were prepared using two-stage emulsification of $\mathrm{W}_{1} / \mathrm{O}$ microemulsion in outer aqueous phase containing biopolymers $\left(\mathrm{W}_{2}\right)$. Three different biopolymers were used in the research: angum gum, arabic gum and protein whey concentrate in two different intensities.

Mutaliyeva et al. (2017) presented the study of biocompatible and non-toxic systems of insulin supplies using double emulsions. When creating macrocapsules, they were heading to preserve its stability and biological activity. The process of emulsion production, stability and characteristics of the produced emulsion were investigated by measurements of size distribution (DLS) and interfacial charge (zeta-potential). Matos et al. (2014) worked on preparation of multiple emulsion of type $\mathrm{W}_{1} / \mathrm{O} / \mathrm{W}_{2}$ containing transresveratrol. They used mechanical agitation and membrane emulsification as techniques to produce emulsion.

The effect of operating parameters in the continuous CTF contactor on multiple emulsion appearance, structure and rheological behaviour was analysed by Dluska and Markowska-Radomska (2010). They used single-stage method to produce multiple emulsion.

Li et al. (2012) worked on emulsion production using magnetic agitator. In order to produce emulsion, they used water, ionic liquid and surfactant. The different type of emulsion was obtained for different water fractions ranging from 0.1 to 0.9 . Multiple emulsion was produced for water fractions ranging from 0.68 to 0.75 . They showed the possibility of producing $\mathrm{W} / \mathrm{IL} / \mathrm{W}$ emulsion using ionic fluid.

The novel approach of making a multiple emulsion by single-step emulsification was presented by Zhang and $\mathrm{Li}$ (2013). The multiple emulsions were prepared by adding the aqueous phase containing water and the xanthan gum to the oil phase containing polydimethylsiloxane polymer and emulsifier. The emulsion was produced while homogenizing through high shear mixer equal to $10,000 \mathrm{rpm}$ for $3 \mathrm{~min}$. After this time, the emulsion which they produced was cooled to the desired temperature while stirring. The samples formulated with different emulsifier concentrations were characterized. The stability of the produced emulsion over time stored at different temperatures was evaluated by microscopic analysis. The studies presented by Zhang and Li (2013) showed the impact of the emulsifier concentration on the emulsion structure as well as on the rheological behaviour.

Major-Godlewska (2019) studied the structure, including the droplet size of the inner oil phase during the formation of the multiple emulsion, and put aside emulsion for 3 and 30 days and then mixed by shaking or mechanical mixing. In her paper, she also presented the rheological properties of the emulsion produced and the emulsion obtained in 30 days from its production.

The rheological properties of the multiple emulsion W/ $\mathrm{Si} / \mathrm{W}$ formation by single-step emulsification was presented and analysed in the paper by Li and Zhang (2015).

The aim of the study presented in this paper was to define structure changes, including inner oil phase drops size and rheological properties during multiple emulsion production using soya lecithin for different rotation frequencies of Smith turbine impeller.

\section{Experimental}

\section{Materials}

Refined sunflower oil produced for Jeronimo Martins Polska S.A. was used as oil phase who was dyed by Sudan III (producer: Eurochem BGD Sp. z o. o.). Distilled water was used as water phase. Lecithin from soya beans (producer: Vemica) was used as emulsifier.

\section{Procedure of the emulsion production}

To dissolve $16 \mathrm{~g}$ of soy lecithin, distilled water was added and stirred with magnetic agitator until mixture homogeneity was obtained. Sunflower oil was coloured by Sudan III. First the water phase with lecithin was poured into the vessel of diameter $D=0.1 \mathrm{~m}$, and then, during stirring with Smith turbine $\left(d_{\mathrm{s}}=0.33 D, Z=6\right)$, oil phase was added (sunflower oil with Sudan III). The part of individual phase contained 70 vol.\% of oil phase and 30 vol\% of water phase. The height of the liquid in the vessel was $H=0.5 D$. Emulsion was prepared in room temperature by using agitated vessel with four planar baffles $(B=0.1 D)$. Geometrical parameters of the vessel are presented in Fig. 1 and were described in detail in paper by Major-Godlewska (2019). The rotation frequency was different for each of the emulsion produced. For the first emulsion produced, the rotation frequency was $500 \mathrm{rpm}$. During the production of the second emulsion, a rotation frequency of $1000 \mathrm{rpm}$ was assumed. The last emulsion produced was created at a rotation frequency of $1500 \mathrm{rpm}$. Samples were taken for description after the stirring time of 15 and $45 \mathrm{~min}$. 


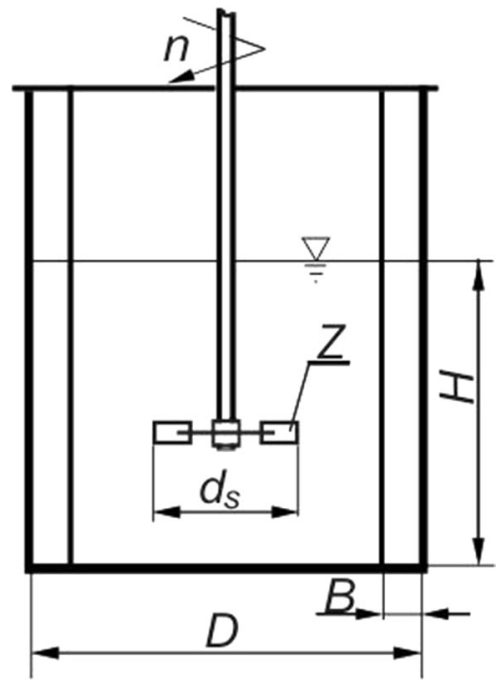

Fig. 1 Geometrical parameters of the vessel

\section{Microstructure studies}

The evaluation of the structure and droplet size of the produced emulsion was performed using the diagnostic inverted microscope OPTA-TECH MW 100, with software and digital camera OPTA-TECH 5MP.

\section{Rheological measurements}

The rheological measurements of multiple emulsion samples were carried out on a rheoviscometer of type RT 10 by firm Haake equipped with the system of two co-axial cylinders (DG 41). The range shear rate, in temperature $23{ }^{\circ} \mathrm{C}$, for each sample was $\gamma<1 ; 50>1 /$ s.

\section{Results and discussion}

\section{Oil in water in oil $(0 / W / 0)$ emulsion}

As the result of the tests of six measurements series, over 4000 drops of the internal oil phase were obtained, which were analysed. Samples of the produced emulsion were taken from the vessel to determine the structure and type of emulsion. Studies determining the type of emulsion produced were carried out using a microscope after $15 \mathrm{~min}$ and after $45 \mathrm{~min}$ of stirring. Images obtained for emulsion stirred with Smith turbine with a rotation frequency of $500 \mathrm{rpm}, 1000 \mathrm{rpm}$ and $1500 \mathrm{rpm}$ are shown in Fig. 2. As it can be seen in Fig. 2, the use of the given emulsion preparation procedure results in the formation of an unstable emulsion described as oil in water in oil $(\mathrm{O} / \mathrm{W} / \mathrm{O})$ emulsion type. Putting the emulsion aside caused gradual, slow phase stratification. Irregular shapes of the water phase were observed in the analysed images. The images obtained enabled to determine the type of emulsion and diameter of the inner oil phase.

The population of inner oil phase drops in the number from 600 to 800 were taken for each series for the analysis. The mean arithmetic diameter $d_{\mathrm{a}}$ defined as $d_{\mathrm{a}}=\Sigma x_{i} d_{i} / \Sigma x_{i}$, median $d_{\mathrm{m}}$ and the mean Sauter diameter $d_{32}$ defined as $d_{32}=\Sigma x_{i} d_{i}^{3} / \Sigma x_{i} d_{i}^{2}$ were calculated with the obtained values. Distribution of inner oil phase drops in the produced emulsion is presented in histogram in Fig. 3. For 15-min stirring time, where the stirrer rotation frequency was $500 \mathrm{rpm}$ (Fig. 3a), 0.78-5.34 $\mu \mathrm{m}$ diameter range drops were $85 \%$ of the analysed population, where the highest number, about $45 \%$ of the analysed population, was drops of diameter from $d=1.82 \mu \mathrm{m}$ to $d=3.52 \mu \mathrm{m}$. The population of droplets with the diameter in the range $1.1-5.37 \mu \mathrm{m}$ accounts about $66 \%$ of the emulsion produced, stirred for $45 \mathrm{~min}$ (Fig. 3b) with the rotation frequency of $500 \mathrm{rpm}$. Comparing the number of $1.82-3.52 \mu \mathrm{m}$ range drops, where 15 -min stirring resulted in the most populous number, when the time was prolonged to $45 \mathrm{~min}$, the number of drops decreased to $25 \%$ of the whole population and it was $20 \%$ less than that in the 15 -min stirring time.

The increase in the rotational frequency of the Smith turbine to $1000 \mathrm{rpm}$ for the same stirring time of $15 \mathrm{~min}$ and 45 min had an impact on the droplet size. Analysing the population of about 650-700 drops presented in the form of the relation of the number of drops $=f(d)$ in Fig. 4a, b, the higher number of drops in the diameter range from 1.1 to $3.32 \mu \mathrm{m}$ was observed, which was about $62 \%$ of the analysed population in 15 -min stirring time than in the 45-min stirring time, where the same diameter drops were $54 \%$ of the analysed population. Analysing the drop diameter in the range of 4.3-6.45 $\mu \mathrm{m}$, it was found that the percentage of droplets with these diameters was similar and for the stirring time of $15 \mathrm{~min}$, it was about $22 \%$, while for $45 \mathrm{~min}$, about $20 \%$.

Analysing the volume of drops which were obtained for the emulsion produced in the Smith turbine, when rotation frequency was $1500 \mathrm{rpm}$, it was found that $47 \%$ of analysed population were drops in the range of 1.1-3.02 $\mu \mathrm{m}$ for the stirring time of $15 \mathrm{~min}$ and $36 \%$ of analysed population of droplets the inner oil phase for stirring time $45 \mathrm{~min}$. Analysing the drop diameter in the range of 4.3-6.45 $\mu \mathrm{m}$ in both cases, i.e. for stirring time of 15 and $45 \mathrm{~min}$, a similar number was obtained representing about $20 \%$ of the analysed drop population.

Table 1 presents the arithmetic diameter $d_{\mathrm{a}}$ which was calculated for the drop population presented in Fig. 3, 4 and 5 in the form of droplets distribution of the inner oil phase of the produced emulsion O/W/O (for different Smith turbine rotation frequencies: 500, 1000, $1500 \mathrm{rpm}$ and two stirring times: 15 and $45 \mathrm{~min}$ ). Then, for the same population of 
(a)

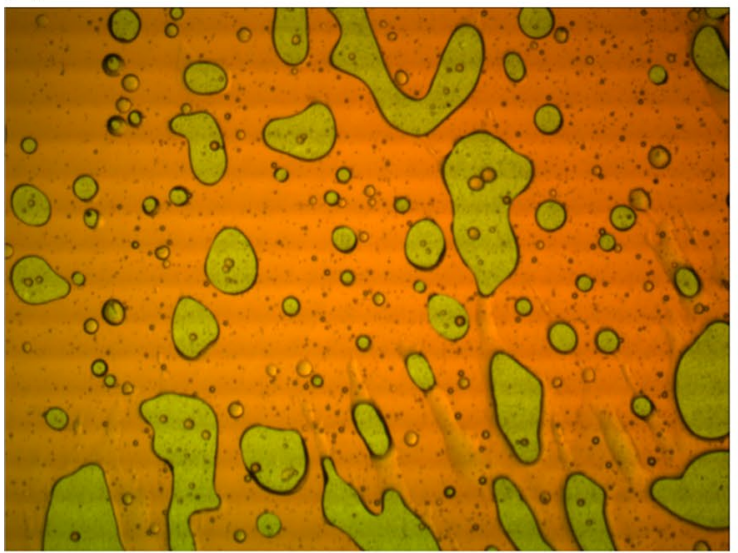

(c)

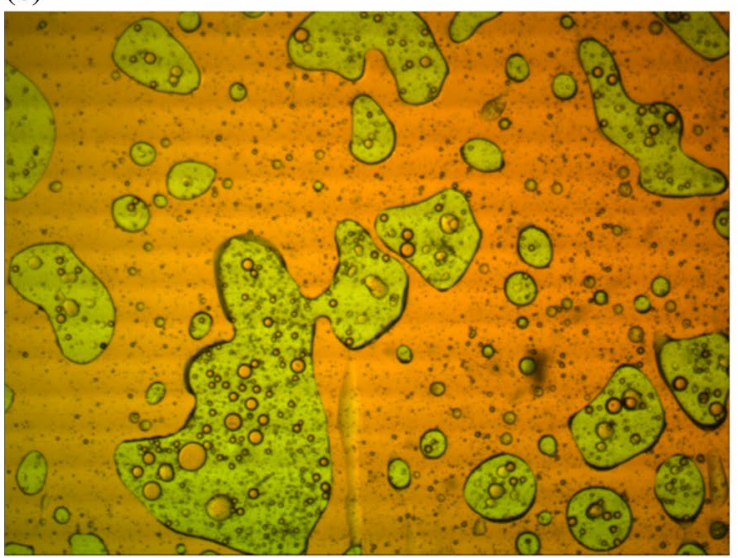

(e)

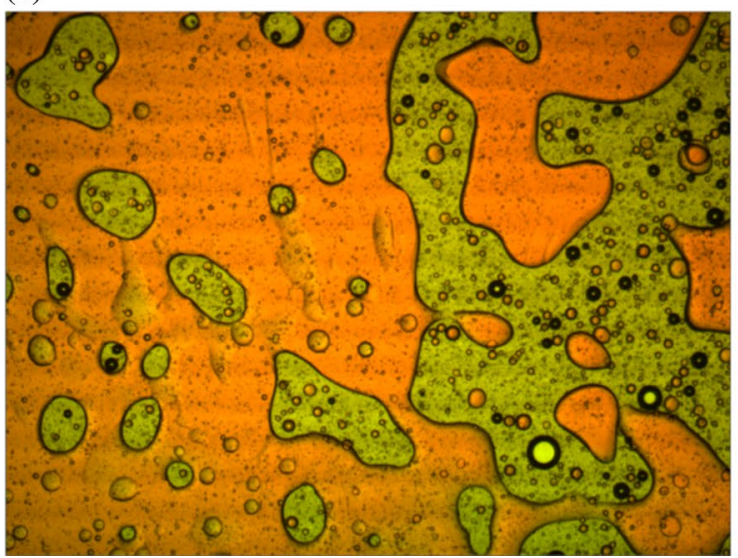

(b)

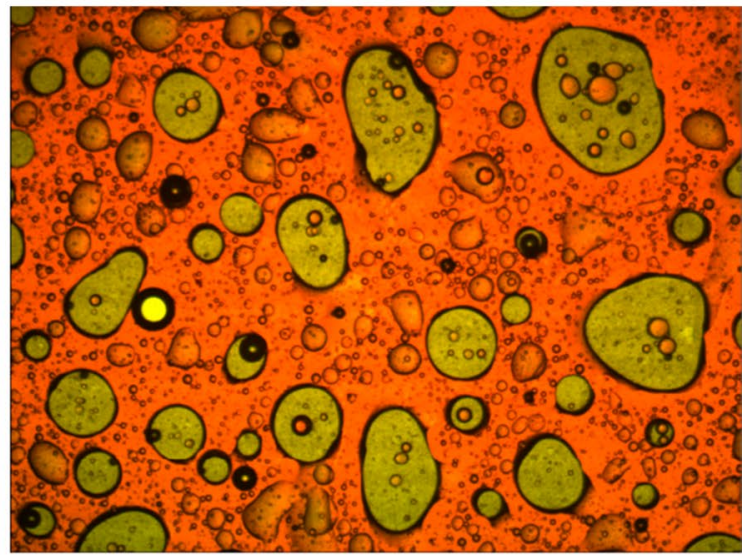

(d)

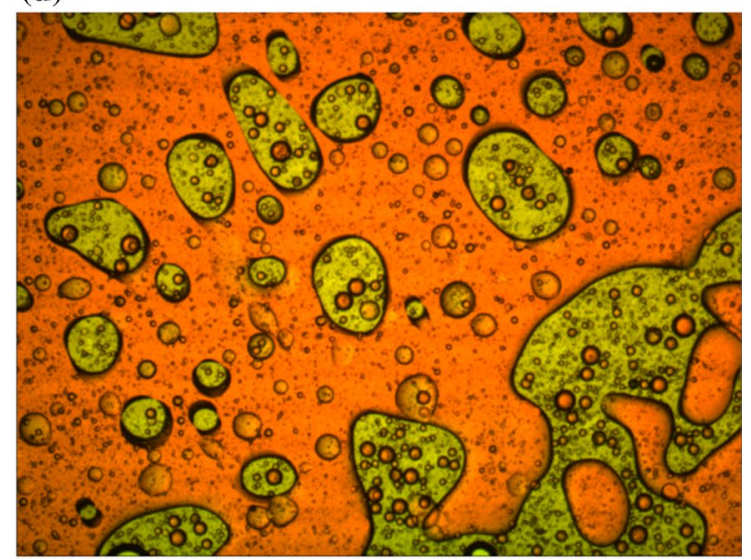

(f)

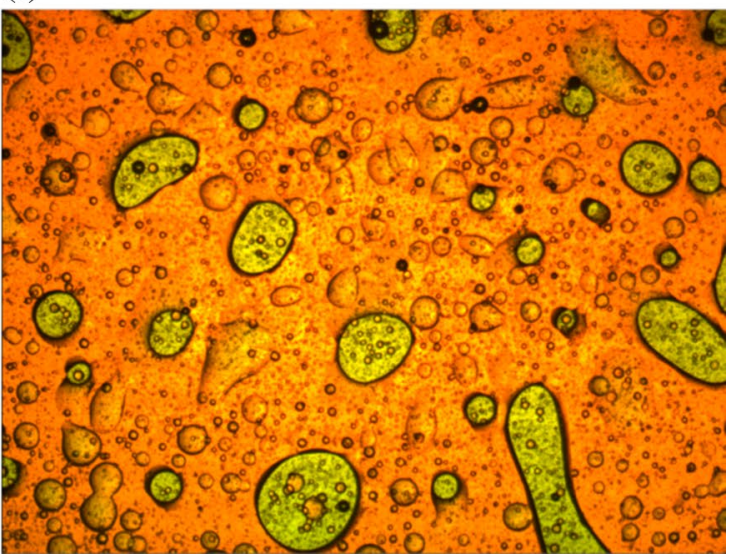

Fig. 2 Images of drops of multiple emulsion produced (O/W/O) for stirring times: a, c, e 15 min, b, d, f 45 min; for the rotation frequency: a, b $500 \mathrm{rpm}, \mathbf{c}, \mathbf{d} 1000 \mathrm{rpm}, \mathbf{e}, \mathbf{f} 1500 \mathrm{rpm}($ enlargement $4 \times)$

internal oil phase droplets, the median $d_{\mathrm{m}}$ and Sauter diameter $d_{32}$ are given in Table 2 .

Analysing the values of the mean Sauter diameter $d_{32}$, it can be seen that in the case of a stirrer frequency of $500 \mathrm{rpm}$ and $1000 \mathrm{rpm}$ when extending the stirring time from $15 \mathrm{~min}$ up to $45 \mathrm{~min}$, the values of the mean Sauter diameter $d_{32}$ increases. It is different when the emulsion produced was stirred with the rotation frequency of $1500 \mathrm{rpm}$. In this case, a decrease in the value of the mean Sauter diameter was observed from $d_{32}=40.6 \mu \mathrm{m}$ for 15 -min stirring to $d_{32}=27.35 \mu \mathrm{m}$ for 45 -min stirring. Analysing the effect of the rotation frequency of the Smith turbine on the mean Sauter diameter $d_{32}$, it was observed that at the stirring time of $15 \mathrm{~min}$, the value $d_{32}$ increases for higher rotation 
Fig. 3 Distribution of inner oil phase drops emulsion $(\mathrm{O} / \mathrm{W} / \mathrm{O})$ stirred with Smith turbine for the rotation frequency of $500 \mathrm{rpm}$ and for stirring times: a $15 \mathrm{~min}$; b $45 \mathrm{~min}$; (-) intensity, (-) summary volume \%
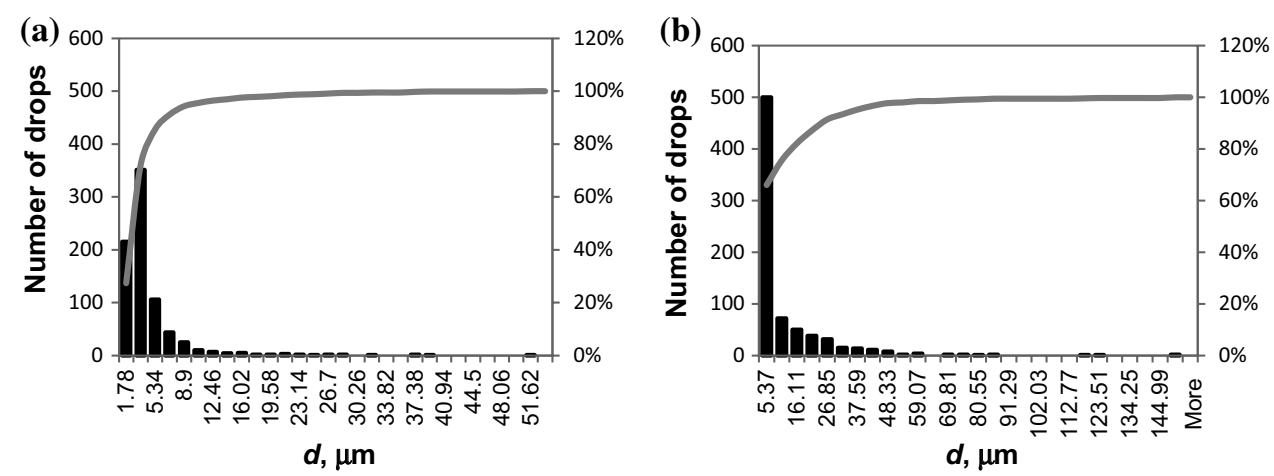

Fig. 4 Distribution of inner oil phase drops emulsion $(\mathrm{O} / \mathrm{W} / \mathrm{O})$ stirred with Smith turbine for the rotation frequency of $1000 \mathrm{rpm}$ and for stirring times: a $15 \mathrm{~min}$; b $45 \mathrm{~min}$; (- $)$ intensity, (-) summary volume \%

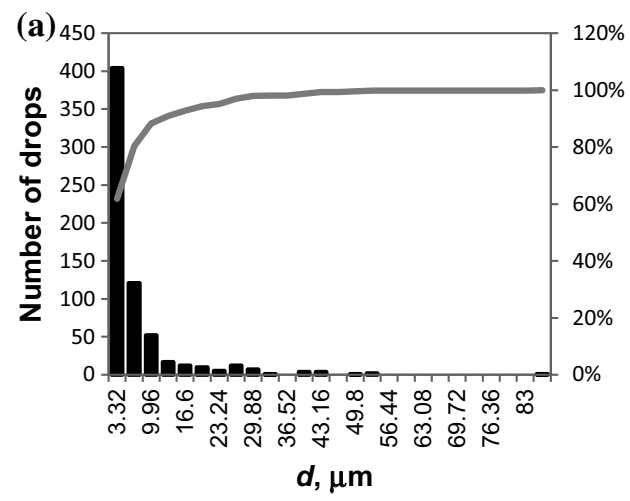

Table 1 The mean arithmetic diameter $d_{\mathrm{a}}$, determined from the population of drops obtained from the emulsion stirred with Smith turbine for the rotation frequency of 500,1000, $1500 \mathrm{rpm}$ and stirring times of 15 and $45 \mathrm{~min}$

\begin{tabular}{lllllll}
\hline Time & & \multicolumn{2}{l}{$15 \mathrm{~min}$} & & & \multicolumn{2}{l}{$45 \mathrm{~min}$} \\
\cline { 3 - 4 } \cline { 6 - 7 } \cline { 6 - 7 } & & Number & $d_{\mathrm{a}}(\mu \mathrm{m})$ & & Number & $d_{\mathrm{a}}(\mu \mathrm{m})$ \\
\hline Rotation frequency & $500 \mathrm{rpm}$ & 786 & 3.77 & & 757 & 9.23 \\
& $1000 \mathrm{rpm}$ & 653 & 5.38 & & 704 & 6.51 \\
& $1500 \mathrm{rpm}$ & 617 & 4.58 & & 660 & 6.95 \\
\hline
\end{tabular}

frequencies. However, for a stirring time of $45 \mathrm{~min}$, the value of the mean Sauter diameter $d_{32}$ tends to decrease as the rotation frequency increases. Analysing the values of the mean alternative diameter $d_{\mathrm{a}}$ and the median $d_{\mathrm{m}}$, it can be stated that for the droplet population adopted for the analysis, larger diameter $d_{\mathrm{a}}$ and $d_{\mathrm{m}}$ droplets were obtained for the emulsion in which samples were taken for testing after $45 \mathrm{~min}$.

The values of the diameter obtained for the emulsion produced with rotation frequency of $500 \mathrm{rpm}$ were compared with the data presented in the paper of Major-Godlewska (2019). It was found that when the amount of soya lecithin added changed, the diameter values changed. For the stirring time of $15 \mathrm{~min}$, larger diameters $d_{\mathrm{a}}, d_{\mathrm{m}}$ and $d_{32}$ were obtained
Fig. 5 Distribution of inner oil phase drops emulsion $(\mathrm{O} / \mathrm{W} / \mathrm{O})$ stirred with Smith turbine for the rotation frequency of $1500 \mathrm{rpm}$ and for stirring times: a $15 \mathrm{~min}$; b $45 \mathrm{~min}$; (-) intensity, (-) summary volume $\%$
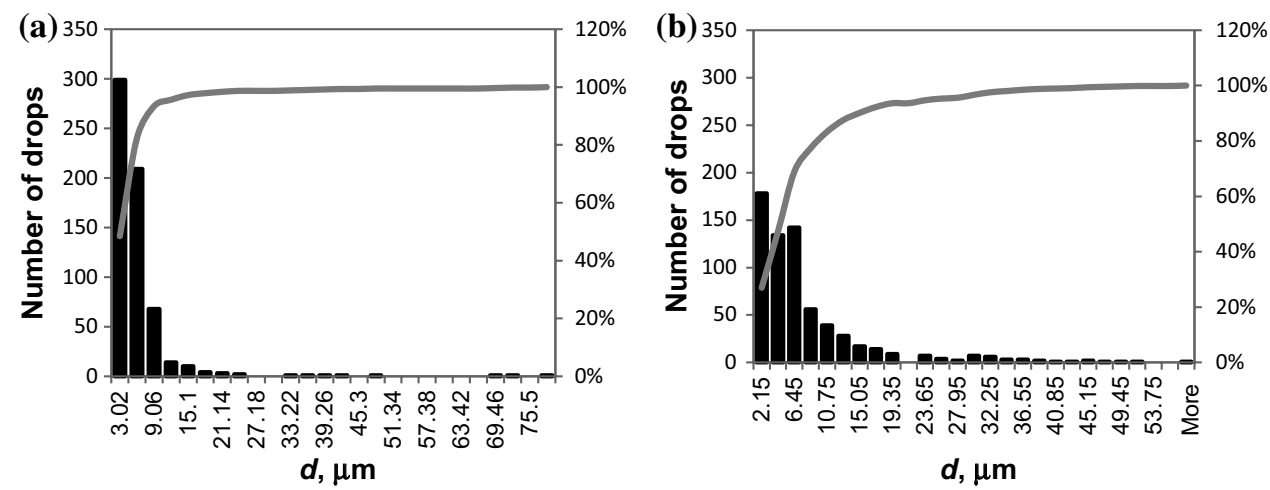
Table 2 Median $d_{\mathrm{m}}$ and mean Sauter diameter $d_{32}$ determined from the population of drops obtained for the emulsion stirred with Smith turbine for the rotation frequency of 500, 1000, $1500 \mathrm{rpm}$ and for stirring times of 15 and $45 \mathrm{~min}$

\begin{tabular}{lllllll}
\hline Time & & \multicolumn{2}{l}{$d_{\mathrm{m}}(\mu \mathrm{m})$} & & \multicolumn{2}{l}{$d_{32}(\mu \mathrm{m})$} \\
\cline { 3 - 4 } \cline { 6 - 7 } \cline { 6 - 7 } & & $15 \mathrm{~min}$ & $45 \mathrm{~min}$ & & $15 \mathrm{~min}$ & $45 \mathrm{~min}$ \\
\hline Rotation frequency & $500 \mathrm{rpm}$ & 2.46 & 3.02 & & 21.16 & 70.98 \\
& $1000 \mathrm{rpm}$ & 2.3 & 2.74 & & 35.43 & 53.2 \\
& $1500 \mathrm{rpm}$ & 3.26 & 4.5 & & 40.6 & 27.35 \\
\hline
\end{tabular}

for the emulsion in which $8 \mathrm{~g}$ of soy lecithin was used for production. If the stirring time is extended to $45 \mathrm{~min}$, this situation is reversed and larger diameter values $d_{\mathrm{a}}, d_{\mathrm{m}}$ and $d_{32}$ were obtained for the emulsion in which $16 \mathrm{~g}$ of soy lecithin was used for production.

The resulting populations of internal oil phase droplets were presented as a data set for $d \leq 20 \mu \mathrm{m}$ assuming a constant range of drop diameter for comparative purposes. It was observed that drops with the diameter of $d \leq 20 \mu \mathrm{m}$ accounted for $93-98 \%$ of the analysed population for 5 series. In the case of the drops population obtained for a stirring time of $45 \mathrm{~min}$, where the emulsion produced was stirred with a rotation frequency of $500 \mathrm{rpm}$, the droplets of the internal oil phase in the range $d \leq 20 \mu \mathrm{m}$ accounted for $86 \%$ of the analysed population. This indicates that $14 \%$ of the analysed population were drops with the diameter larger than $20 \mu \mathrm{m}$. This value is greater than the value obtained when stirring lasted $15 \mathrm{~min}$ at a rotation frequency of $500 \mathrm{rpm}$. At that time, drops with the diameter of $d>20 \mu \mathrm{m}$ were only about $2 \%$ of the analysed population. A comparison of the obtained drops for $d \leq 20 \mu \mathrm{m}$ is presented in Fig. 6. The highest number of drops equal to 330 (Fig. 6a) was obtained in the range of 2.01-4 $\mu \mathrm{m}$ for the system in which the emulsion produced was stirred for $15 \mathrm{~min}$ with a rotation frequency of $500 \mathrm{rpm}$. Comparing the number of drops in the range of $0-2 \mu \mathrm{m}$, it was observed that the few drops, i.e. 205 for a stirring time of $15 \mathrm{~min}$ and 172 for a stirring time of $45 \mathrm{~min}$, were obtained for emulsion stirred with a rotation frequency of $1500 \mathrm{rpm}$ (Fig. 6c). In the case of the droplets diameter in the range 4.01-6 $\mu \mathrm{m}$ or 6.01-8 $\mu \mathrm{m}$, a different distribution was observed. The highest number of drops was obtained for the emulsion produced
Fig. 6 Distribution of inner oil phase drops emulsion $(\mathrm{O} / \mathrm{W} / \mathrm{O})$ for drop diameter of $d \leq 20 \mu \mathrm{m}$ where the produced emulsion was stirred with Smith turbine with the rotation frequency a $500 \mathrm{rpm}$, b $1000 \mathrm{rpm}$, c $1500 \mathrm{rpm}$ and for stirring times $(\square) 15$ and ( $\square$ ) $45 \mathrm{~min}$

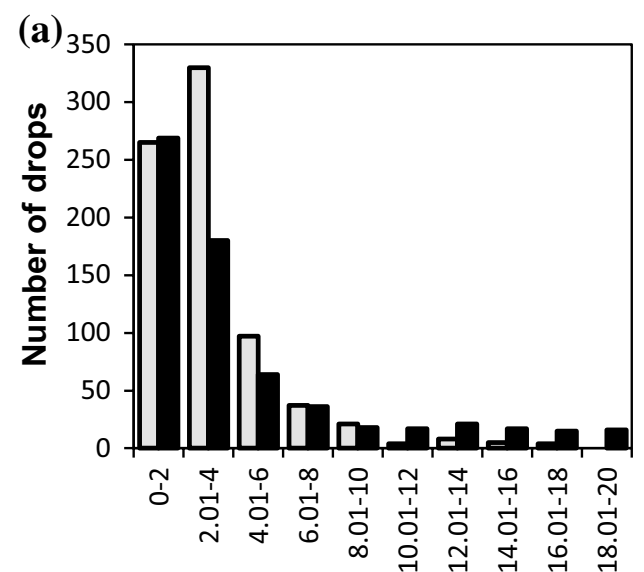

Range of $d, \mu \mathrm{m}$

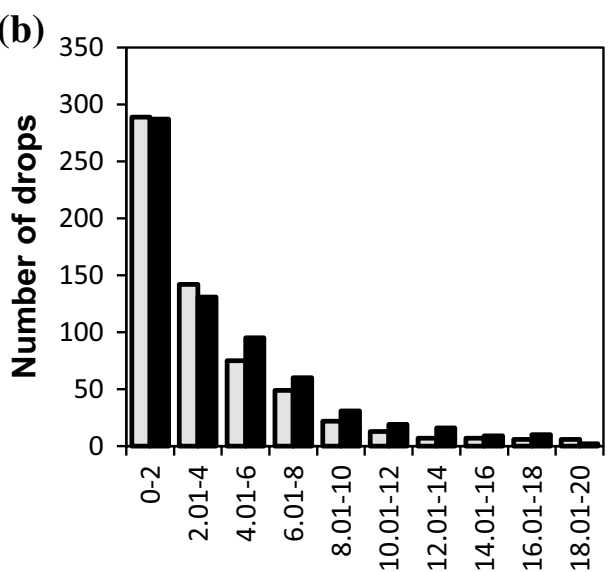

Range of $d, \mu \mathrm{m}$

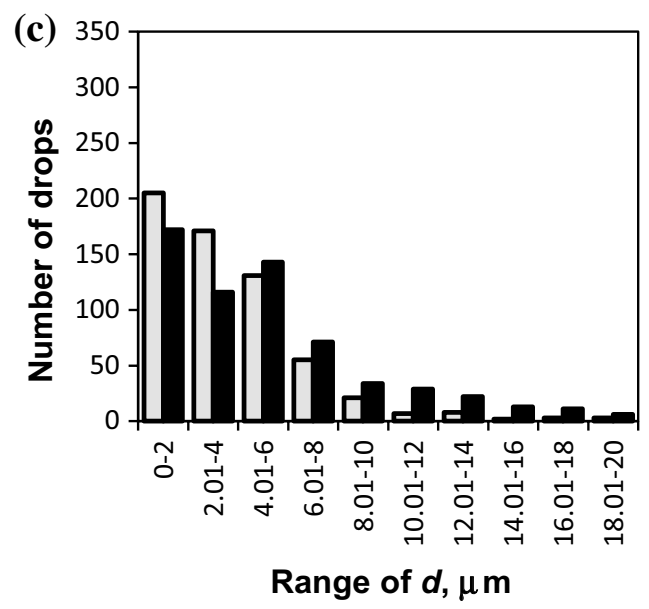


with a rotation frequency of $1500 \mathrm{rpm}$ (Fig. 6c). For both stirring times of $15 \mathrm{~min}$ and $45 \mathrm{~min}$, the drop population in the range of $d<4.01-6>\mu \mathrm{m}$ were 131 or 143 drops, respectively, and in the range of $d<6.01-8>\mu \mathrm{m}$ were 55 or 71 , respectively. The number of droplets of the internal oil phase for the diameter range of 4.01-6 $\mu \mathrm{m}$ was close to 100 drops or less than 100 drops at the rotation frequency of $500 \mathrm{rpm}$ (Fig. 6a) or $1000 \mathrm{rpm}$ (Fig. 6b). Comparing the number of drops with diameter in the range from 10 to $18 \mu \mathrm{m}$ at the same rotation frequencies, the higher number of drops was observed (Fig. 6) when the emulsion produced was stirred for $45 \mathrm{~min}$ compared to the number of drops obtained for the stirring time of $15 \mathrm{~min}$.

\section{Rheological properties}

The rheological properties of the emulsion produced were also analysed. The knowledge of the rheological properties is important in the produced processes and in emulsion final production phases. The values of shear rate $\gamma$ and shear stress $\tau$ are presented as a relation $\tau=\mathrm{f}(\gamma)$ in Fig. 7. In the analysed stirring time, i.e. $15 \mathrm{~min}$ and $45 \mathrm{~min}$, it was observed that the values of shear stress $\tau$ and shear rate $\gamma$ can be described using Herschel-Bulkley model (Fig. 7a). The values of constant and exponent of Herschel-Bulkley model obtained on the basis of experimental data are presented in Table 3. The mean mistake in each of the analysed cases was not greater than $3 \%$.

Increasing the stirring time from $15 \mathrm{~min}$ to $45 \mathrm{~min}$ has no significant influence on the rheological properties of the emulsion produced when Smith turbine with rotation frequency equal to $500 \mathrm{rpm}$ is used during the production process (Fig. 7a). When Smith turbine rotation frequency was $1500 \mathrm{rpm}$, it was observed at shear rate $\gamma, 1 / \mathrm{s} \leq 7$ values shear stress $\tau$ for both stirring times ( $15 \mathrm{~min}$ and $45 \mathrm{~min}$ ) were similar. Only for $\gamma, 1 / \mathrm{s}>7$, the difference was visible, and assuming constant shear rate $\gamma$, higher shear stress values $\tau$ were obtained for emulsion produced
Fig. 7 Relation $\tau=\mathrm{f}(\gamma)$ for the produced emulsion stirred for 15 and $45 \mathrm{~min}$ with the rotation frequency a $500 \mathrm{rpm}$, b $1000 \mathrm{rpm}$, c $1500 \mathrm{rpm}$; )15 min, ( $\diamond) 45 \mathrm{~min}$
Table 3 Equations describing the rheological properties of the produced emulsion, with the mean relative error $\Delta= \pm 3 \%$ for each equation
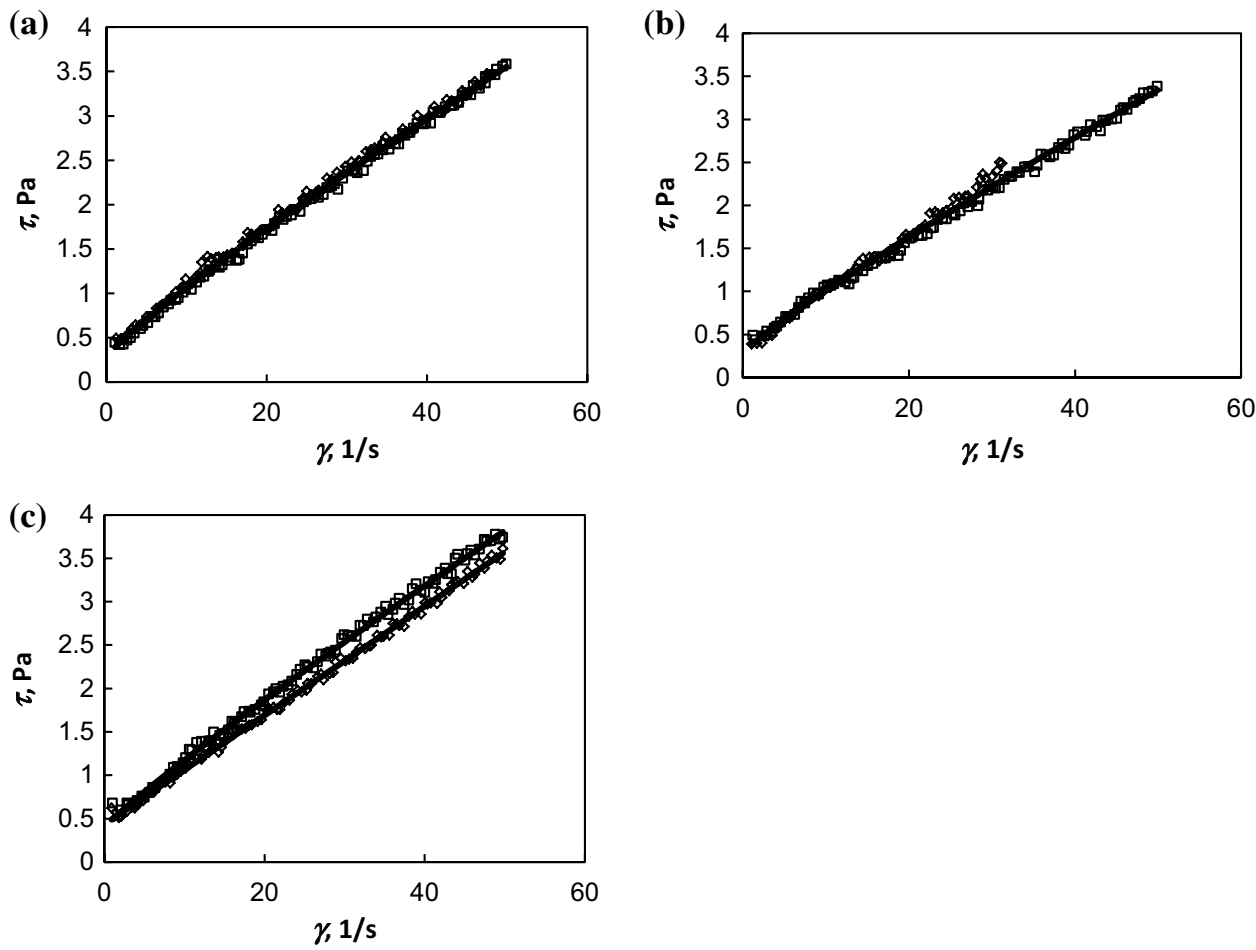

\begin{tabular}{lllll}
\hline $\begin{array}{l}\text { Rotation fre- } \\
\text { quency, rpm }\end{array}$ & Time (min) & Equation & Range shear rate $(1 / \mathrm{s})$ & Eq. \\
\hline 500 & 15 and 45 & $\tau=0.289+\left(0.0994 \cdot \gamma^{0.893}\right)$ & $\gamma \in(1-50)$ \\
1000 & 15 & $\tau=0.282+\left(0.0927 \cdot \gamma^{0.894}\right)$ & $\gamma \in(1-50)$ \\
& 45 & & $\gamma \in(1-30)$ \\
1500 & 15 & $\tau=0.396+\left(0.0936 \cdot \gamma^{0.92}\right)$ & $\gamma \in(1-50)$ \\
& 45 & $\tau=0.434+(0.0628 \cdot \gamma)$ & $\gamma \in(1-50)$ & \\
& & &
\end{tabular}




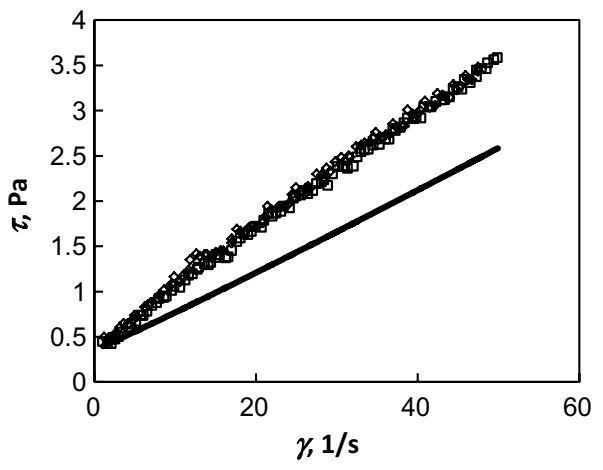

Fig. 8 Relation $\tau=\mathrm{f}(\gamma)$ for the produced emulsion stirred for 15 and $45 \mathrm{~min}$ with the rotation frequency of $500 \mathrm{rpm} ; 16 \mathrm{~g}$ of soy lecithinpoints: $(\square) 15 \mathrm{~min},(\diamond) 45 \mathrm{~min} ; 8 \mathrm{~g}$ soy lecithin—line (presented by Major-Godlewska (2019))

in 15 min compared to data obtained for a stirred emulsion for $45 \mathrm{~min}$. For the more precise description of the rheological properties, when the mean relative error was not more than $\pm 3 \%$, experimental data were described by Herschel-Bulkley and Bingham model (Table 3). The rheological properties obtained for the emulsion stirred with the rotation frequency of $1500 \mathrm{rpm}$ for $15 \mathrm{~min}$ were described by Herschel-Bulkley model, whereas the data obtained for emulsion stirred for $45 \mathrm{~min}$ were described by Bingham model. The values of both equations are presented in Fig. 7c, in the form of dependencies $\tau=\mathrm{f}(\gamma)$.

Comparing the results presented by Major-Godlewska (2019), for the emulsion produced in the Smith turbine, with the stirred rotation frequency of $500 \mathrm{rpm}$ when $8 \mathrm{~g}$ of soy lecithin was used with the results presented in this paper (500 rpm frequency and $16 \mathrm{~g}$ of soy lecithin), it was found that the amount of lecithin used to produce the emulsion affects its rheological properties. In Fig. 8, the data were presented in the form of equation $\tau=\mathrm{f}(\gamma)$. The values obtained when $16 \mathrm{~g}$ of lecithin was used during the emulsion production where the stirrer rotation frequency was $500 \mathrm{rpm}$ were marked as points. The values obtained with the equation presented by Major-Godlewska (2019) were marked as line. The larger amount of lecithin in the emulsion increases the value of shear stress $\tau$ assuming the same constant shear rate $\gamma$. At the shear rate $\gamma=51 / \mathrm{s}$, the value of shear stress $\tau$ for the emulsion with $16 \mathrm{~g}$ of lecithin is about $27 \%$ greater than value $\tau$ obtained for the emulsion with $8 \mathrm{~g}$ of lecithin. At higher shear rates $\gamma$, the difference in the values of $\tau$ increases, for example when $\gamma$ is about $401 / \mathrm{s}$, the difference in the value of $\tau$ is about $40 \%$.

\section{Conclusions}

On the basis of the data obtained in 6 series of measurements (over 4000 inner oil phase drops) during emulsion production in the $\operatorname{tank}(D=0.1 \mathrm{~m}$ and $H=0.5 D)$ with Smith turbine, sunflower oil (70 vol\%) and distilled water (30 vol\%) with $16 \mathrm{~g}$ of soya lecithin produced multiple unstable emulsion of type oil in water in oil $(\mathrm{O} / \mathrm{W} / \mathrm{O})$ in 15 and $45 \mathrm{~min}$ of stirring, with three different stirrer rotation frequencies $(500 \mathrm{rpm}$, $1000 \mathrm{rpm}$ and $1500 \mathrm{rpm}$ ).

Both the stirring time and the frequency of rotation of the stirrer influence the size and distribution of inner oil phase drops. It was found that using three different rotation frequencies (500 rpm, $1000 \mathrm{rpm}$ and $1500 \mathrm{rpm}$ ) of the Smith turbine stirrer, higher values of mean arithmetic diameter drop $d_{\mathrm{a}}$ and median $d_{\mathrm{m}}$ were obtained when the produced emulsion was stirred for $45 \mathrm{~min}$. In the case of mean Sauter diameter $d_{32}$, the influence of rotation frequency was visible. For the stirring time of $15 \mathrm{~min}$, the values of the mean Sauter diameter were greater for each of the higher frequencies of rotation of the stirrer. The greatest value of $d_{32}=40.6 \mu \mathrm{m}$ in the studied range was obtained when the produced emulsion was stirred with rotation frequency equal to $1500 \mathrm{rpm}$. For stirring time equal to $45 \mathrm{~min}$, the greatest value of $d_{32}=70.98 \mu \mathrm{m}$ was obtained for frequency rotation equal to $500 \mathrm{rpm}$, and it was found that with increasing frequency of stirrer rotation, the value of the mean Sauter diameter $d_{32}$ decreases.

When the emulsion produced was stirred with the rotation frequency of 500 or $1000 \mathrm{rpm}$ in the analysed shear rate range, there were no major differences in shear stress values $\tau$ at given shear rates $\gamma$. When the stirrer rotation frequency during the emulsion production was $1500 \mathrm{rpm}$, the influence of stirring time was visible. This is noticeable in the obtained shear stress values for given shear rates presented in the form of a flow curve $\tau=\mathrm{f}(\gamma)$, for the range $\gamma, 1 / \mathrm{s}>7$.

Rheological properties of the emulsion produced are described by Herschel-Bulkley or Bingham model presented in Table 3.

The amount of soya lecithin used to produce the emulsion affects the rheological properties. Higher shear stress values at given shear rate values were obtained for the emulsion for which a larger amount of soy lecithin was used.

Open Access This article is licensed under a Creative Commons Attribution 4.0 International License, which permits use, sharing, adaptation, distribution and reproduction in any medium or format, as long as you give appropriate credit to the original author(s) and the source, provide a link to the Creative Commons licence, and indicate if changes were made. The images or other third party material in this article are included in the article's Creative Commons licence, unless indicated otherwise in a credit line to the material. If material is not included in the article's Creative Commons licence and your intended use is not permitted by statutory regulation or exceeds the permitted use, you will 
need to obtain permission directly from the copyright holder. To view a copy of this licence, visit http://creativecommons.org/licenses/by/4.0/.

\section{References}

Aditya NP, Aditya S, Yang H, Kim HW, Park SO, Ko S (2015) Codelivery of hydrophobic curcumin and hydrophilic catechin by a water-in-oil-in-water double emulsion. Food Chem 173:7-13. https://doi.org/10.1016/j.foodchem.2014.09.131

Bou R, Cofrades S, Jimenez-Colmenero F (2014) Physicochemical properties and riboflavin encapsulation in double emulsions with different lipid sources, LWT Food Sci. Technol 59:621-628. https ://doi.org/10.1016/j.lwt.2014.06.044

Dłuska E, Markowska-Radomska A (2010) Regimes of multiple emulsion of $\mathrm{W}_{1} / \mathrm{O} / \mathrm{W}_{2}$ and $\mathrm{O}_{1} / \mathrm{W} / \mathrm{O}_{2}$ type in the continuous CouetteTaylor flow contactor. Chem Eng Technol 1:113-120. https://doi. org/10.1002/ceat.200900278

Garti N (1997) Double emulsions-scope, limitations and new achievements. Colloids Surfaces A: Physicochem Eng Aspects 123124:233-246. https://doi.org/10.1016/S0927-7757(96)03809-5

Li F, Zhang W (2015) Stability and rheology of W/Si/W multiple emulsions with polydimethylsiloxane. Colloids and Surfaces A: physicochem Eng Aspects 470:290-296. https://doi.org/10.1016/j. colsurfa.2015.02.001

Li J, Zhang J, Han B, Zhao Y, Yang G (2012) Formation of multiple water-in-ionic liquid-in-water emulsions. J Colloid Interface Sci 368:395-399. https://doi.org/10.1016/j.jcis.2011.10.083

Mahammadi A, Jafari SM, Esfanjani AF, Akhavan S (2016) Application of nano-encapsulated olive left extract in controlling the oxidative stability of soybean oil. Food Chem 190:513-519. https ://doi.org/10.1016/j.foodchem.2015.05.115

Major-Godlewska M (2019) Evaluation of drops dimensions in time and rheological properties of the multiple emulsion. Chem Pap 73:2073-2080. https://doi.org/10.1007/s11696-019-00754-5

Matos M, Gutierrez G, Coca J, Pazos C (2014) Preparation of water-inoil-in-water $\left(\mathrm{W}_{1} / \mathrm{O} / \mathrm{W}_{2}\right)$ double emulsions containing trans-resveratrol. Colloids Surfaces A: Physicochem Eng Aspects 442:69-79. https://doi.org/10.1016/j.colsurfa.2013.05.065

Matsumoto S, Kita Y, Yonezawa D (1976) An attempt at preparing water-in-oil-in-water multiple-phase emulsion. J Colloid Interface Sci 57:353-361. https://doi.org/10.1016/0021-9797(76)90210-1

Mehrania MA, Jafari SM, Makhmal-Zadeh BS, Maghsoudlou Y (2017) Rheological and release properties of double nano-emulsions containing crocin prepared with Angum gum, Arabic gum and whey protein. Food Hydrocoll 66:259-267. https://doi. org/10.1016/j.foodhyd.2016.11.033

Mutaliyeva B, Grigoriev D, Madybekova G, Sharipova A, Aidarova S, Saparbekova A, Miller R (2017) Microencapsulation of insulin and its release using w/o/w double emulsion method. Colloids Surfaces A: Physicochem Eng Aspects 521:147-152. https://doi. org/10.1016/j.colsurfa.2016.10.041

Perez-Moral N, Watt S, Wilde P (2014) Comparative study of the stability of multiple emulsions containing a gelled or aqueous internal phase. Food Hydrocoll 42:215-222. https://doi.org/10.1016/j. foodhyd.2014.05.023

Schuch A, Deiters P, Henne J, Kohler K, Schuchmann HP (2013) Production of W/O/W (water-in-oil-in-water) multiple emulsions: droplet breakup and release of water. J Colloid Interface Sci 402:157-164. https://doi.org/10.1016/j.jcis.2013.03.066

Sung MR, Xiao H, Decker EA, Mc Clements DJ (2015) Fabrication, characterization and properties of filled hydrogel particles formed by the emulsion-template method. J Food Eng 155:16-21. https:// doi.org/10.1016/j.jfoodeng.2015.01.007

Surh J, Vladisavljevic GT, Mun S, McClements DJ (2007) Preparation and characterization of water/oil and water/oil/water emulsions containing biopolymer-gelled water droplets. J Agric Food Chem 55:175-184. https://doi.org/10.1021/jf061637q

Ursica L, Tita D, Palici I, Tita B, Vlaia V (2005) Particle size analysis of some water/oil/water multiple emulsions. J Pharm Anal 37:931-936. https://doi.org/10.1016/j.jpba.2004.10.055

Vasiljevic D, Parojcic J, Primorac M, Vuleta G (2006) An investigation into the characteristics and drug release properties of multiple W/O/W emulsion systems containing low concentration of lipophilic polymeric emulsifier. Int J Pharm 309:171-177. https://doi. org/10.1016/j.ijpharm.2005.11.034

Yamanaka Y, Kobayashi I, Neves MA, Ichikawa S, Uemura K, Nakajima M (2017) Formulation of W/O/W emulsions loaded with short-chain fatty acid and their stability improvement by layer-bylayer deposition using. LWT Food Sci Technol 76:344-350. https ://doi.org/10.1016/j.1wt.2016.07.063

Zhang W, Li F (2013) Preparation and characterization of multiple emulsions (W/Si/W) by single-step emulsification. Colloids Surfaces A: Physicochem Eng Aspects 423:98-103. https://doi. org/10.1016/j.colsurfa.2013.02.004

Publisher's Note Springer Nature remains neutral with regard to jurisdictional claims in published maps and institutional affiliations. 